\title{
Sobre los 25 Años de la Declaración de Río sobre el Medio ambiente y el Desarrollo
}

Teresa Fajardo del CAstillo

\author{
Profesora Titular de Derecho Internacional Público \\ Universidad de Granada \\ teresa.fajardo@ugr.es
}

La Declaración de Río sobre el Medio ambiente y el desarrollo ${ }^{1}$ que fue adoptada en la Conferencia de las Naciones Unidas sobre el Medio ambiente y el Desarrollo de 1992 cumplirá este mes de junio 25 años. Mirar hacia atrás para examinar su influencia en este período histórico -una historia vivida en mi casoen el que mi generación creyó vislumbrar tras el fin de la Guerra Fría y la caída del muro de Berlín, un tiempo de cambios posibles que finalmente no tuvieron lugar, me lleva a constatar luces y sombras, éxitos y fracasos, que en ningún caso pueden hacernos olvidar que la Declaración de Río y sus principios establecieron un horizonte normativo al que aún hoy se dirigen las acciones de las organizaciones internacionales y de los Estados en sus distintos ámbitos de responsabilidad política y legislativa. La Declaración de Río formuló el principio del desarrollo sostenible y muchos otros principios que informan hoy el Derecho internacional y el derecho interno de los Estados y que llevaron a afirmar una nueva forma de ejercicio de la soberanía de manera que se viera limitada por la función de proteger el medio ambiente (Principio 2). Estos principios llevaron también a nuevas formas de ver el medio ambiente y el desarrollo -sostenible o no- que enraizaron más allá de la disciplina del derecho en la economía, la sociología, la filosofía, la geografía...

La Declaración de Río, fruto de un esmerado consenso, respondía a una estructura compleja porque a partir de un preámbulo sucinto, sus 27 principios unos, de naturaleza política y otros con desigual intensidad normativa- pueden

\footnotetext{
${ }^{1}$ Disponible en Internet http://www.un.org/spanish/esa/sustdev/documents/declaracionrio.htm .

[DOI: http://dx.doi.org/10.17345/rcda.1792] 1
} 
agruparse en razón de tres objetivos: articular una visión del medio ambiente desde el desarrollo, proponer las directrices básicas que debían inspirar las políticas públicas medioambientales, y consolidar los principios normativos de la Declaración de Estocolmo de 1972 a la vez que formular nuevos, llamados a formar parte tanto del ordenamiento jurídico internacional a través de su incorporación en los tratados internacionales, como de los ordenamientos internos.

A pesar de estas mimbres, la Declaración de Río fue vista en su tiempo como una botella medio llena porque no llegó a abordar todos los problemas o a formular todos los principios del Derecho internacional del medio ambiente, ${ }^{2} 0$ como una botella medio vacía por la subordinación que hacía de la protección del medio ambiente al desarrollo económico en algunos de sus principios ${ }^{3}$ (véase Principios 2, 3, 4, 5, 8), lo que había sido una exigencia de los países en vías de desarrollo, que había llevado a adulterar la formulación original de los Principios de la Declaración de Estocolmo sobre el Medio Humano y, en especial, el Principio 21, al que en el Principio 2 se le había añadido la palabra desarrollo: De conformidad con la Carta de las Naciones Unidas y los principios del derecho internacional, los Estados tienen el derecho soberano de aprovechar sus propios recursos según sus propias políticas ambientales $y$ de desarrollo, y la responsabilidad de velar por que las actividades realizadas dentro de su jurisdicción o bajo su control no causen daños al medio ambiente de otros Estados o de zonas que estén fuera de los límites de la jurisdicción nacional.

El origen de esta visión que unía el medio ambiente al desarrollo se encuentra en el Informe Brundtlant, "Nuestro Futuro en Común" en el que se funda la Declaración de Río. ${ }^{4}$ Este informe llevó a cabo un diagnóstico de los males del planeta a partir de dos causas principales: la pobreza y el modelo de

\footnotetext{
${ }^{2}$ Vid. KISS, A., "The Rio Declaration on Environment and Development”, en CAMPIGLIO, L. et al. (Eds.), The Environment after Rio: International Law and Economics, Graham \& Trotman / M. Nijhoff, 1994, p. 63, VIÑUALES, J., "The Rio Declaration: A Preliminary Study", en VIÑUALES, J. (Ed.), The Rio Declaration on Environment and Development. A Commentary, Oxford University Press, 2015, p. 2.

3 Vid. PALLEMAERTS, M., "International Environmental Law from Stockholm to Rio: Back to the Future?", RECIEL, Vol. 1, p. 256.

${ }^{4}$ El informe de la Comisión Mundial del Medio ambiente y del Desarrollo Sostenible elaborado bajo la dirección de la ex presidenta noruega Gro Harlem Brundlant puede consultarse en red en http://www.undocuments.net/our-common-future.pdf. En castellano fue publicado en 1988 por Alianza Editorial.
} 
producción y consumo de los países desarrollados (Principios 3, 5, 6, 8), que lejos de ser problemas aislados se retroalimentan en un círculo vicioso en el que los países pobres producen con un estrecho margen de beneficio para abastecer la demanda de los países desarrollados que quieren consumir de todo, todo el tiempo y a bajos precios. Considero plenamente vigente este diagnóstico, aunque con ciertos matices. En la Conferencia de Río de 1992, para solucionar los problemas derivados de los excesos del modelo de consumo y de producción, se confió en que la ciencia y las nuevas tecnologías podrían aportar desde la eficiencia energética un remedio a la sobreexplotación: se confiaba en que con menos recursos se produjeran más bienes y con un menor coste energético. Esta esperanza, sin embargo, se vio traicionada por la demanda insaciable de más y nuevos productos de consumo y energía. La pobreza que había que erradicar (Principio 5) traía también causa de un pasado colonial y de un mercado mundial regido por una ley de dependencia perpetua de la oferta de los países en vías de desarrollo de la demanda de los desarrollados. Este paradigma se ha visto alterado con la aparición de la escasez de recursos que ha convertido a países en vías de desarrollo en potencias emergentes de un nuevo orden mundial, donde los Estados se clasifican ahora también en función de su biocapacidad y de su contribución a la contaminación global o al cambio climático. Ello ha llevado, sin embargo, a que se cuestione la fuerza con la que se esgrime el Principio 7 de las Responsabilidades comunes pero diferenciadas, que vinculado estrechamente a los principios de Desarrollo sostenible (Principio 1) y de equidad (Principio 3), justificaba el régimen de obligaciones asimétrico de la mayor parte de los tratados internacionales para la protección del medio ambiente, ${ }^{5}$ y cuya afirmación y posterior cuestionamiento se ve reflejado en la Convención Marco sobre el Cambio Climático y su desarrollo normativo con el Protocolo de Kioto y el Acuerdo de París donde se afirma en su Artículo 2.2 que "se aplicará de modo que refleje la equidad y el principio de las responsabilidades comunes pero diferenciadas y las capacidades respectivas, a la luz de las diferentes circunstancias nacionales", pero en el que se da la espalda a las reivindicaciones de compensación por la responsabilidad histórica por los efectos del desarrollo.

\footnotetext{
${ }^{5}$ Vid. JUSTE RUIZ, J., Derecho Internacional del Medio ambiente, McGraw Hill, Madrid, 1998.
} 
Respecto a la influencia de los principios y de las directrices políticas de la Declaración de Río que han inspirado la gobernanza internacional y doméstica y el hacer de las políticas públicas de los últimos 25 años, sólo decir que es innegable pero que han sufrido la erosión de su invocación en vano y, también, que han sido relegados a los márgenes de la agenda política por la crisis económica. El Principio del Desarrollo Sostenible se ha invocado -no por su naturaleza o su intensidad normativa sino por el halo de legitimidad que confiere a todo acto normativo o ejecutivo que persigue convencer de lo necesario que es proteger el medio ambiente, y no sólo al medio ambiente, porque tras su fragmentación en la Conferencia de Johannesburgo sobre el Desarrollo Sostenible de 2002, sirve también para sustentar políticas sociales y económicas. Y como afirma Ángel Rodrigo en su obra "El Desafío del Desarrollo Sostenible", el abuso de este principio lo ha puesto al borde de la irrelevancia. ${ }^{6}$

A pesar del deterioro del contexto económico y social, de especial valor son los principios políticos que han promovido la apertura de los procesos de toma de decisiones a los actores no estatales (Principio 10), empoderando así al ciudadano y a las ONGs, a las mujeres (Principio 20), a los jóvenes (Principio 21 ), a las poblaciones indígenas y otras comunidades locales (Principio 22). Sin su papel no cabe entender los últimos desarrollos de la justicia ambiental por la que se reivindica una mayor protección del medio ambiente per se por parte de las autoridades públicas y una protección de las generaciones futuras frente a los desastres a los que el cambio climático puede condenar el planeta. ${ }^{7}$ Estos actores no estatales buscan ahora trascender la figura del Estado-nación cuando sus fronteras nacionales se convierten en una barricada para evitar confrontar los problemas globales.

Respecto a los principios normativos de la Declaración de Río, a pesar de su heterogeneidad y del carácter contestado de algunos de ellos, constituyen hoy parte del ordenamiento jurídico internacional y de los ordenamientos internos, y también de una creciente jurisprudencia internacional que se ha hecho eco de estos principios en el Tribunal Internacional de Justicia, en el

\footnotetext{
${ }^{6}$ Vid. RODRIGO, A., El Desafio del Desarrollo Sostenible. Los principios de Derecho internacional relativos al desarrollo sostenible, Marcial Pons, 2015, p. 10.

${ }^{7}$ Vid. BORRÁS PENTINAT, S., «Movimientos para la justicia climática global: replanteando el escenario internacional del cambio climático», Relaciones Internacionales, Número 33, Octubre 2016 - Enero 2017, Grupo de Estudios de Relaciones Internacionales (GERI) - UAM, pp. 97-119.
} 
Tribunal del Derecho del Mar o en el Tribunal de Justicia de la Unión Europea y, también, en la jurisprudencia nacional donde se les otorga, a veces, un valor metajurídico. Estos principios jurídicos, en tanto que expectativas normativas propias del soft law o en tanto que normas consuetudinarias, informan el derecho internacional general a través de la redefinición de la soberanía del Estado con la función de protección del medio ambiente. Estos principios también caracterizan como sub-sistema al Derecho internacional del medio ambiente con el principio de no causar daño (Principios 2 y 13) y el principio de las responsabilidades comunes pero diferenciadas (Principio 7).

Los principios reguladores de las relaciones entre los Estados y que conformarían el marco de cooperación internacional para la protección del medio ambiente (Principios 2, 7, 9, 12, 13, 14, 18, 19, 24, 25, 26, 27), se han consolidado como normas consuetudinarias que, sin embargo, sufren un déficit de aplicación y cumplimiento que en ocasiones lleva a omitirlos en los tratados internacionales donde deberían ser codificados, siendo quizás el ejemplo más grave el Acuerdo de París sobre el cambio climático en el que se evitó incorporar la responsabilidad en todas sus posibles acepciones. ${ }^{8}$ Todos requieren la adopción de medidas internacionales e internas que nunca llegan o son insuficientes o cuando son adoptadas no se les asignan los recursos necesarios para garantizar su cumplimiento: como en el caso del Principio 13 que las pide para regular la responsabilidad y la indemnización respecto de las víctimas de la contaminación y otros daños ambientales, o de los Principios 18 y 19 que - con el accidente de Chernobil en el recuerdo-, requieren que los Estados se comuniquen los accidentes y desastres e intercambien la información pertinente sobre las actividades que pudieran tener efectos transfronterizos. El coste de la inacción es que hoy, por ejemplo, las actividades que el Principio 14 pedía perseguir a los Estados --"actividades y sustancias que causen degradación ambiental grave o se consideren nocivas para la salud humana"--, constituyen los crímenes ambientales transnacionales más rentables.

\footnotetext{
${ }^{8}$ Vid. PIGRAU, A. " Laudato Si”, Revista Catalana de Dret Ambiental, Vol. VI Núm. 1 (2015): 1 - 10 Editorial- y CAMPINS I ERITJA, M., "De Kioto a París: ¿Evolución o Involución de las Negociaciones Internacionales sobre el Cambio Climático?", Instituto Español de Estudios Estratégicos, Nº61/2015, 15 de Junio de 2015, ieee.es.
} 
De igual modo, aquellos principios que vinculaban al medio ambiente con la paz y la seguridad (Principios 24 y 25) siguen a la espera de una acción más vigorosa mientras la Comisión de Derecho Internacional finaliza su Proyecto de artículos sobre la Protección del medio ambiente en relación al conflicto armado ${ }^{9}$; o en el caso del Principio 23 de que el derecho internacional humanitario se respete. Así, este principio que afirma que "Deben protegerse el medio ambiente y los recursos naturales de los pueblos sometidos a opresión, dominación y ocupación" se enfrenta a una realidad como la del Sahara Occidental o la de Palestina en la que los ocupantes que deberían ser los "trustees" de sus patrimonios naturales, explotan los recursos agrícolas y pesqueros, los recursos mineros y el agua para su beneficio doméstico en contra del Derecho internacional humanitario que lo prohíbe.

Los principios destinados a ser incorporados por los Estados en sus ordenamientos jurídicos internos adoptando leyes medioambientales eficaces "sin olvidar el coste que ello podría suponer para los países en vías de desarrollo" (Principio 11) como el de Precaución (Principio 15), o el de internalización de los costes ambientales (Principio16) o el de la evaluación de impacto ambiental (Principio 17), son reconocidos formalmente en casi todos los países, si bien su eficacia y su grado de cumplimiento depende de la fortaleza de sus instituciones y el modo en que éstas garantizan el estado de derecho en clave ambiental. La práctica de los Estados muestra la inconsistencia entre su adhesión a los principios y su deficiente aplicación tanto en el plano internacional como en el interno, y con ello, su deficiente compromiso con el último principio, el 27, que establecía que "Los Estados y las personas deberán cooperar de buena fe y con espíritu de solidaridad en la aplicación de los principios consagrados en esta Declaración y en el ulterior desarrollo del derecho internacional en la esfera del desarrollo sostenible".

Una plena aplicación de los principios de la Declaración de Río habría necesitado de una mayor institucionalización del sub-sistema del Derecho internacional del medio ambiente. Sin embargo, los Estados siguen negándose

\footnotetext{
${ }^{9}$ International Law Commission, Sixty-eighth session, Geneva, 2 May-10 June and 4 July-12 August 2016, Protection of the environment in relation to armed conflict, A/CN.4/L.870/Rev.1
} 
a crear una organización internacional del medio ambiente. En el caso del PNUMA -el Programa de las Naciones Unidas para el Medio ambiente-, aunque en la Conferencia de Río de 2012 su fortalecimiento fuera uno se de los objetivos, aún está lejos de estar a la altura de los retos del planeta. La UNEA, la Asamblea de las Naciones Unidas para el medio ambiente que se creó en esta conferencia como necesario foro universal y ensayo de futuros progresos, aún sigue a la espera de que unos recursos adecuados permita una mayor ambición en sus resoluciones.

La presentación que acabo de hacer de la Declaración de Río y de sus principios podría considerarse la propia de un observador que ve la botella medio vacía. Ello se debe a que los retos de la aplicación y el cumplimiento que ha de afrontar cualquier norma de Derecho internacional son especialmente crueles con la Declaración de Río y sus principios, --mezcolanza de buenos deseos, directrices políticas, expectativas normativas y normas consuetudinarias--. Sin embargo, una descripción de la botella como medio llena es posible si consideramos que la Declaración de Río y sus principios -y lo que éstos encierran de la Declaración de Estocolmo- aportan una nueva manera de percibir el mundo, haciendo visibles los grandes problemas medioambientales y la ligazón que existe entre pobreza y medio ambiente, modernidad ${ }^{10} \mathrm{y}$ contaminación y agotamiento de los recursos y cambio climático. Y cabe preguntarnos si la Declaración de Río y sus principios tienen la capacidad de proyectarse 25 años más en el futuro. Y la respuesta es claramente que sí, porque aunque el futuro sea incierto ${ }^{11}$, las herramientas normativas con las que contamos ahora son un desarrollo importante de la Declaración de Río, que

\footnotetext{
${ }^{10}$ Para una visión crítica véase JARIA I MANZANO, J., "Recuperar la iniciativa", Revista Catalana de Dret Ambiental, Vol. VII Núm. 1 (2016): 1 - 8 -Editorial-
}

\footnotetext{
${ }^{11}$ En su último e inacabado libro, el sociólogo alemán Ulrich Beck consideraba que nos encontramos ante una situación de metamorfosis del mundo que supera a la noción de cambio en la sociedad porque "Change brings a characteristic future of modernity into focus, namely permanent transformation, while basic concepts and the certainties that support them remain constant. Metamorphosis, by contrast, destabilizes these certainties of modern society. It shifts the focus to 'being in the world' and 'seeing the world', to events and processes which are unintended, which generally go unnoticed, which prevail beyond the domains of politics and democracy as side effects of radical technical and economic modernization," véase Ulrich BECK, The Metamorphosis of the World, Polity Press, Cambridge, 2016, p. xi.
} 
informan ahora los Objetivos de Desarrollo Sostenible de las Naciones Unidas adoptados en 2015 para inspirar su acción más allá, hasta 2030. 